\title{
Optimization of a pre-improvement support system for large underground excavation
}

\author{
Ki-Il Song ${ }^{1}$, Gye-Chun $\mathrm{Cho}^{2}$, Young-Jong $\mathrm{Sim}^{3}$, In-Mo Lee ${ }^{4}$ \\ 1,2,3 Dept. of Civil and Envir. Engrg., Korea Advanced Institute of Science and Technology (KAIST), \\ Daejeon, Korea \\ ${ }^{4}$ Dept. of Civil and Envir. Engrg., Korea University, Seoul, Korea
}

\begin{abstract}
The demand for large underground space is increasing as various needs arise. As the scale of underground space increases, failure and collapse risks accordingly rise, primarily due to higher uncertainty of properties and a lower arching effect. Therefore, proper primary support systems (e.g., rock bolt and shotcrete) are required to prevent failure of the tunnel face during excavation and large vertical displacement at the tunnel crown and ground surface for safe tunnel construction. Additionally, a pre-improvement support system must be applied before excavation and during the excavation process, depending on the tunnel scale. The necessity of a pre-improvement support system for large underground excavation is verified based on numerical analyses. Important design parameters of the pre-improvement support system are chosen and their effectiveness in terms of tunnel support is analyzed through parametric studies according to various tunnel scales. The results suggest that the reinforcement area around the tunnel is not linearly dependent on the tunnel scale and the required reinforced area for a large tunnel is wider than that of the linearly obtained reinforced area as the tunnel scale increases. Finally, this paper presents the optimized design parameters of a pre-improvement support system according to tunnel scale and also presents more general evidence of the need for a pre-improvement support system in large underground spaces.
\end{abstract}

\section{INTRODUCTION}

Recently, large underground space has been frequently requested for the construction of large underground shopping centers, storage of natural gas and oil, highway tunnels with large sections, etc. As the scale of underground space increases, the risks of failure and collapse become higher due to higher uncertainties of ground properties and the lower arching effect. In this case, properly designed primary support systems (e.g., rock bolt and shotcrete) are required to prevent failure of the tunnel face and large vertical displacement at the tunnel crown and ground surface during excavation. Additionally, a pre-improvement support system has to be applied before and during the excavation process as primary support systems alone cannot ensure tunnel safety. Herein, pre-improvement support system refers to the umbrella arch method (Barisone et al., 1982), which combines the advantages of a modern forepoling system with the grouting injection method. Indeed, it is a major task for tunnel engineers to design support systems for large excavation cavities to prevent the occurrence of collapse or failure.

A pre-improvement support system should prevent excessive vertical displacement at the ground surface and tunnel crown, derive the long-term arching effect for stabilization, prevent collapse, and improve the stand-up time for large underground excavation. A number of studies have addressed this issue (Korbin and Brekke, 1976; Barisone et al., 1982; Pelizza and Peila, 1993; Bernaud, 1995; Fizzarotti, 2001; and Lee et al., 2003). Various pre-improvement auxiliary techniques for tunnelling 
are used to reinforce the ground, resulting in improved tunnel stability. The selection and the construction of auxiliary support systems mainly depend on the geological characteristics of the tunnel area, such as water table condition and rock mass quality.

The umbrella arch method is often used as an auxiliary technique for highly fractured rock or shallow depth tunnelling. This method has been studied primarily in terms of small scale tunnel diameter. However, it has been noted that the behaviours of a large underground space are somewhat different from those of small size tunnels (Jun et al., 2004). Therefore, in this study, the effect of preimprovement support systems (i.e., the umbrella arch method) is analyzed using a 3D finite element method with an emphasis on large section tunnels.

\section{3D FEM ANALYSIS}

In this study, a three-dimensional finite element program, PENTAGON-3D, was used for the numerical modelling of a pre-improvement support system in tunnels with large sections. For the numerical analysis, we employ a pre-improvement support system consisting of an area reinforced by grouting and pipe, as shown in Figure 1(a). The reinforced area by grouting was analyzed as a compressive shell element from a hexahedron element and the pipe is considered as a linear elastic beam element to support the vertical load. The increase in the strength of the ground by grouting is reviewed in Table 1. Based on this, it is assumed here that the strength of the reinforced area by grouting is twice that of the non-improved area.

Three different types of finite element mesh were used for three different tunnel diameters, i.e., $\mathrm{D}=10 \mathrm{~m}, 20 \mathrm{~m}$, and $30 \mathrm{~m}$. The depth of the tunnel crown is located $20 \mathrm{~m}$ below the ground surface for all cases. In total, 81 cases have performed, varying three design parameters (Figure 1(b)). First, the effect of the installation angle of the pipe, $\alpha$, has been analyzed for $10^{\circ}, 20^{\circ}$, and $30^{\circ}$ with respect to each tunnel diameter. Second, the effect of the overlap length, OL, has been analyzed for $0 \mathrm{~m}, 3 \mathrm{~m}$, and $6 \mathrm{~m}$ with respect to each tunnel diameter. Third, three different lengths of pipes, $\mathrm{L}$, (i.e., $\mathrm{L}=6 \mathrm{~m}, 12 \mathrm{~m}$, and $18 \mathrm{~m}$ ) have been applied for each tunnel diameter. Excavation length per cycle is $3 \mathrm{~m}$ and the total number of cycles is 13 , resulting in a total length of $39 \mathrm{~m}$. The material property of the ground is assumed to be weathered rock. Material properties used for modelling are summarized in Table 2.

The same construction sequence is applied for all cases. Pipe is installed first and then the upper part of the tunnel is excavated. Soft shotcrete and rock bolt are constructed for the upper part of the tunnel. Shotcrete hardening and pipe installation are performed simultaneously in the subsequent stage for the upper part of the tunnel. The upper part for the next stage and the bottom part for the current stage are excavated. Shotcrete and rockbolt for the upper part of the next stage and the bottom part of current stage are constructed simultaneously. The construction cycle is repeated with this procedure. In this study it is assumed that groundwater does not exist.

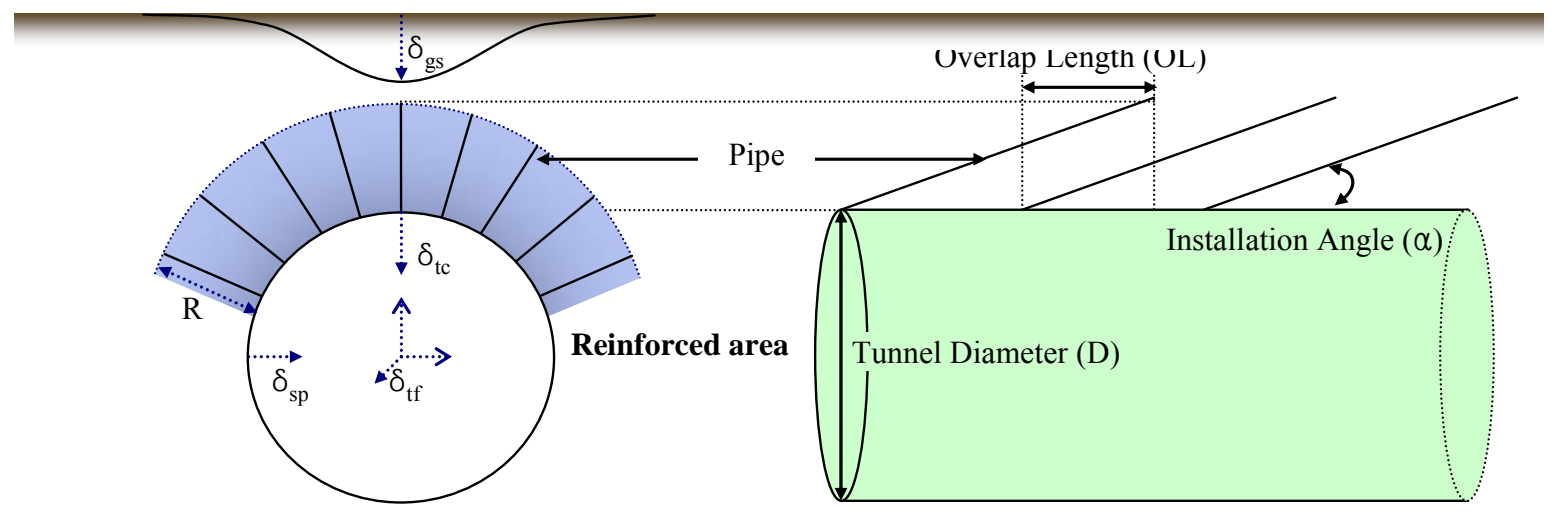

(a) Transverse section with displacement parameters

(b) Longitudinal section with three selected design parameters

Figure 1. Schematic diagram of problem (Note: $\delta_{\mathrm{sp}}=$ horizontal displacement at tunnel springline; $\delta_{\mathrm{tf}}=$ horizontal displacement at tunnel face; $\delta_{\mathrm{gs}}=$ ground surface settlement; $\delta_{\mathrm{tc}}=$ vertical displacement at tunnel crown) 
Table 1. Effect of improvement by grouting on the ground strength

\begin{tabular}{|c|c|c|c|c|}
\hline \multirow{2}{*}{ Literature } & \multicolumn{2}{|c|}{ Young's Modulus (kPa) } & \multirow{2}{*}{ Ground Material } & \multirow{2}{*}{ Method } \\
\hline & Before & After & & \\
\hline \multirow{2}{*}{ Lee and Kim (1993) } & $3 \mathrm{E} 4$ & $1 \mathrm{E} 6$ & \multirow{2}{*}{ Alluvial deposit } & Grouting \\
\hline & $5 \mathrm{E} 4$ & 2E6 & & Jet Grouting \\
\hline \multirow{2}{*}{ Kim et al. (1993) } & $2 \mathrm{E} 4$ & $4 \mathrm{E} 4$ & Alluvial deposit & Horizontal Jet Grout \\
\hline & $5 \mathrm{E} 5$ & $8 \mathrm{E} 5$ & Weathered Rock & Roofing \\
\hline Kim (1994) & $5.1 \mathrm{E} 5$ & 2E6 & Weathered Rock & Cement Grouting \\
\hline Kim et al. (1995) & $2.5 \mathrm{E} 4$ & $4.736 \mathrm{E} 4$ & Weathered Soil & SPRMS Grouting \\
\hline
\end{tabular}

Note : SPRMS Grouting = Steel Pipe Reinforced Multi Step Grouting

Table 2. Material properties for numerical modeling

\begin{tabular}{lcccccc}
\hline \multicolumn{1}{c}{ Property } & $\begin{array}{c}\text { Weathered } \\
\text { rock }\end{array}$ & $\begin{array}{c}\text { Improved } \\
\text { Weathered Rock }\end{array}$ & Pipe & Rock bolt & $\begin{array}{c}\text { Soft } \\
\text { Shotcrete }\end{array}$ & $\begin{array}{c}\text { Hard } \\
\text { Shotcrete }\end{array}$ \\
\hline Young's Modulus $[\mathrm{kPa}]$ & $1 \mathrm{E} 6$ & $2 \mathrm{E} 6$ & $7.72 \mathrm{E} 7$ & $2.1 \mathrm{E} 8$ & $5 \mathrm{E} 6$ & $1.5 \mathrm{E} 7$ \\
Area $\left[\mathrm{m}^{2}\right]$ & - & - & 0.002027 & 0.0005 & - & - \\
Unit Weight $\left[\mathrm{kN} / \mathrm{m}^{3}\right]$ & 22 & 22 & 33 & 78.5 & 24 & 24 \\
Poisson's Ratio & 0.3 & 0.27 & 0.2 & - & 0.2 & 0.2 \\
Thickness [cm] & - & - & - & - & 10 & 16 \\
Cohesion $[\mathrm{kPa}]$ & 50 & 75 & - & - & - & - \\
Friction Angle $\left[{ }^{\circ}\right]$ & 33 & 33 & - & - & - & - \\
Ko & 0.5 & 0.5 & - & - & - & - \\
\hline
\end{tabular}

\section{IMPORTANCE OF PRE-IMPROVEMENT SUPPORT SYSTEM}

In general, collapse and failure at a tunnel face occur progressively when the ground material is weathered rock or soil. Therefore, the measurement of ground surface settlement $\left(\delta_{\mathrm{gs}}\right)$ and horizontal displacement at the tunnel face $\left(\delta_{\mathrm{tf}}\right)$ is a critical issue that requires consideration for tunnelling. $3 \mathrm{~m}$ bench cutting, which is recommended for safer excavation, has been modelled.

Figure 2 provides a comparison of computed ground surface settlement with respect to the three different tunnel scales. The large tunnel $(D=30 \mathrm{~m})$ shows greater ground surface settlement compared to the small tunnel $(\mathrm{D}=10 \mathrm{~m})$. The effect of preimprovement on ground surface settlement is more significant for the large diameter tunnel than the small tunnel $\mathrm{D}=10 \mathrm{~m}$ ) where the installation angle of pipe is $30^{\circ}$ and the overlap length is $6 \mathrm{~m}$. For example, ground surface settlement for the large tunnel $(D=30 \mathrm{~m})$ is reduced by $0.97 \mathrm{~mm}$ compared to the nonpre-improved condition whereas that for the small scale tunnel $(D=10 \mathrm{~m})$ is reduced by $0.27 \mathrm{~mm}$. It could thereby be concluded that a pre-improvement support system should be applied for the large tunnel to decrease ground surface settlement.

As expected, higher horizontal displacement at the tunnel face occurred for larger tunnel diameter (Figure 3) where multi-drift excavation is not introduced. However, the effect of pre-improvement support on the horizontal displacement at the tunnel face is not significant in this analysis at $\alpha=10^{\circ}$ and $\mathrm{OL}=6 \mathrm{~m}$. Therefore, a novel pre-improvement support system for tunnel face is needed for safe large tunnel

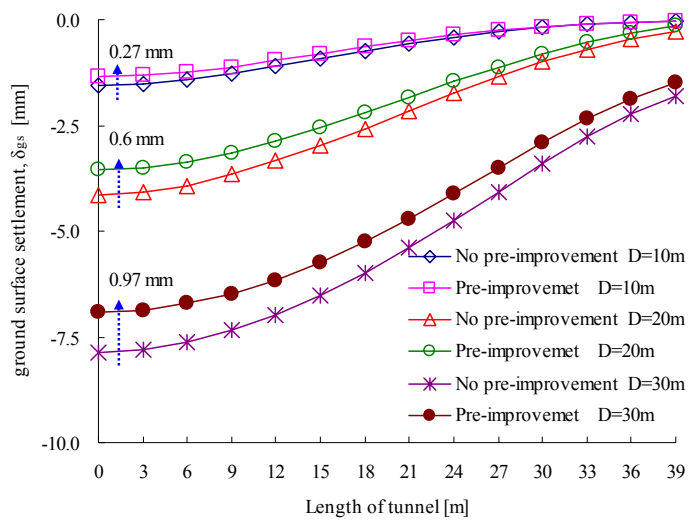

Figure 2. Ground surface settlement

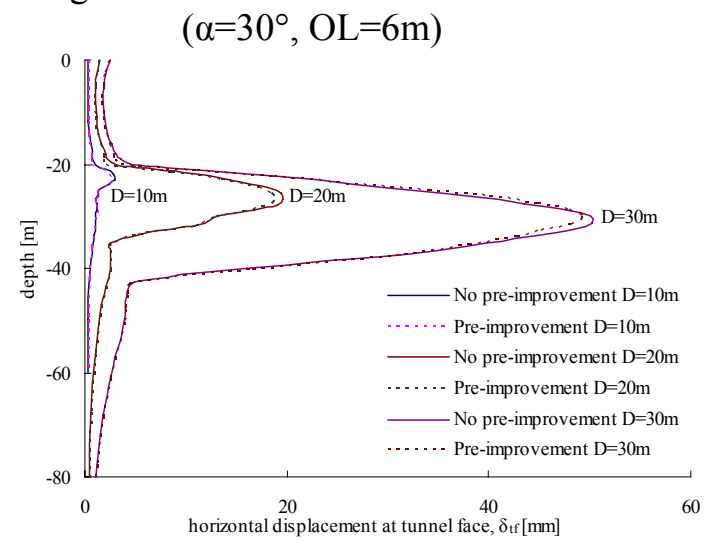

Figure 3. Horizontal displacement at tunnel face $\left(\alpha=10^{\circ}, \mathrm{OL}=6 \mathrm{~m}\right)$ 
excavation. Furthermore, a new excavation pattern should be suggested to minimize the horizontal displacement at the tunnel face.

\section{Parametric study}

Numerical analyses were performed, varying three different design parameters, installation angle of the pipe $(\alpha)$, overlap length (OL), and pipe length (L) (Figure 1(b)). For all cases, vertical displacement at the tunnel crown and ground surface, horizontal displacement at the springline, maximum bending compressive stress, and axial force of the pipe were calculated. The obtained vertical displacement for each design parameter was plotted at a location of $24 \mathrm{~m}$ from the beginning of the excavation.

The maximum stresses acting on the shotcrete and the maximum axial forces of the pipe, respectively, were assessed throughout the construction sequences. For all cases, pipe spacing along the tunnel perimeter is $2 \mathrm{~m}$.

\subsection{Installation angle of the pipe $(\alpha)$}

The reinforced area (Figure 1(a)) depends on the installation angle of the pipe. For example, when the pipe is installed at an angle of $30^{\circ}$ and the length of pipe is $12 \mathrm{~m}$, the reinforced range is $6.9 \mathrm{~m}$ from the excavation surface. As the installation angle of pipe increases (e.g., $\alpha=30^{\circ}$ ), the pre-improvement efficiency for the tunnel crown and ground surface is improved (Figure 4). For example, the vertical displacement at the tunnel crown could be reduced by $10 \sim 12 \%$ when the pipe angle is varied from $10^{\circ}$ to $30^{\circ}$. On the other hand, as the installation angle of pipe decreases (e.g., $\alpha=10^{\circ}$ ), the control effect for horizontal displacement at the springline and tunnel face is improved (Figure 5). For example, the horizontal displacement at the tunnel springline could be reduced by $12.6 \%$ when the pipe angle is varied from $30^{\circ}$ to $10^{\circ}$ in the case of $\mathrm{D}=30 \mathrm{~m}$. Therefore, the installation angle of pipe $(\alpha)$ and reinforced range (R) must be compromised according to consideration of the geological conditions around the tunnel construction area.

From figure 4, we can confirm that a more effective and efficient pre-improvement support system is required for large excavation. The vertical displacement of the large tunnel at the crown is larger than that of a small diameter tunnel, even though the ratio of tunnel radius and the reinforced range is the same. This relationship can be expressed as follows,

$$
\frac{R_{\text {Large }}}{D_{\text {Large }}}=\frac{R_{\text {Small }}}{D_{\text {Small }}}, \quad \delta_{\text {Large }}>\delta_{\text {Small }}
$$

where $R_{\text {Large }}$ and $R_{\text {Small }}$ are the reinforced range of the large and small scale tunnel, respectively. $\delta_{\text {Large }}$ and $\delta_{\text {Small }}$ are the measured displacements of the large and small scale tunnel, respectively.

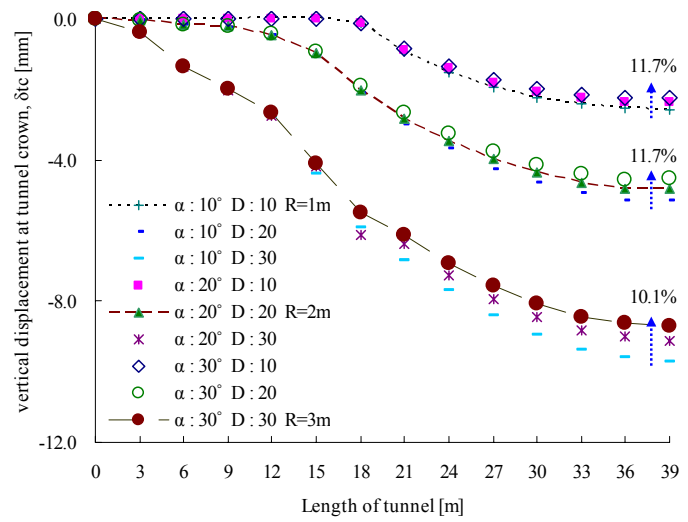

Figure 4. Effect of $\alpha$ on vertical displacement at tunnel crown $(\mathrm{OL}=6 \mathrm{~m})$

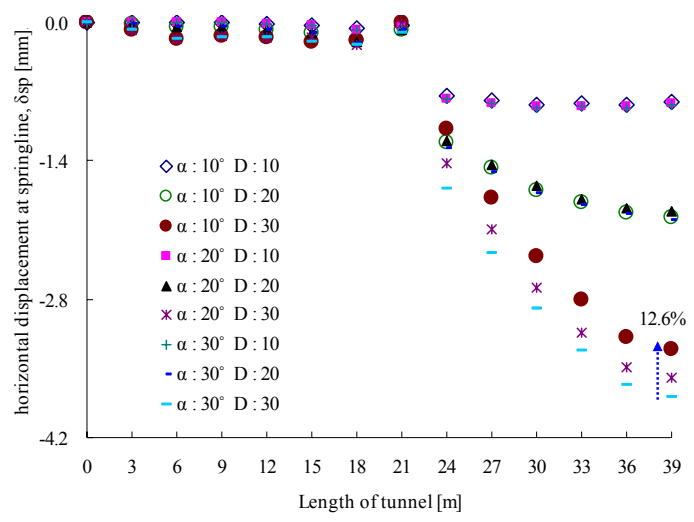

Figure 5. Effect of $\alpha$ on horizontal displacement at tunnel springline $(\mathrm{OL}=6 \mathrm{~m})$ 


\subsection{Overlap length}

Figure 6 shows the effect of the overlap length of the pipe. In this analysis, the effect of the overlap length of the pipe is not significant in terms of ground surface settlement regardless of the design parameters, although the ground surface settlement for the large tunnel is slightly greater than that of the small diameter tunnel. In practice, the overlapping area undergoes a boring process for installation of the pipe, resulting in disturbance of the overlapped area. Further experimental and theoretical study should be performed to evaluate the real mechanical behaviour of the reinforced zone.

\subsection{Pipe length}

As expected, as the length of the pipe increases, the vertical displacement at the tunnel crown and the ground surface settlement decrease (Figures 7 and 8). The vertical displacement at the tunnel crown can be reduced by $13 \%$ when the pipe length is varied from $6 \mathrm{~m}$ to $18 \mathrm{~m}$ (Figure 7). Also, ground surface settlement can be reduced by $13 \%$ (Figure 8). From figure 9, the maximum bending stresses of shotcrete and the maximum axial force of the pipe decrease as the length of the pipe increases. The stress reduction ratio acting on the shotcrete increases as the tunnel scale and the pipe length increase. This means that the large scale tunnel distributes the stress acting on the shotcrete lining effectively, provided that longer pipe is used. Also, as the pipe length increases, the axial forces for the three different scale tunnels decrease and converge (Figure 9). This indicates that construction with long pipe provides long-term stability and small stress intensity acting on the shortcrete for a large section tunnel. However, construction availability and economical efficiency need to be considered.

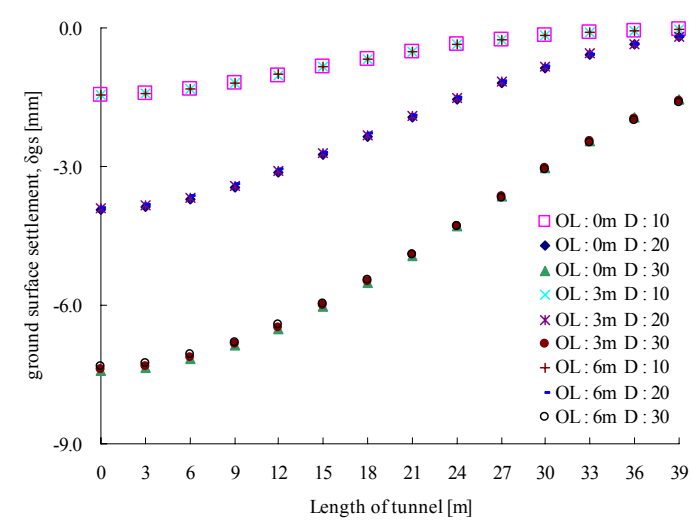

Figure 6. Effect of overlap length on ground surface settlement $\left(\alpha=30^{\circ}, \mathrm{OL}=6 \mathrm{~m}\right)$

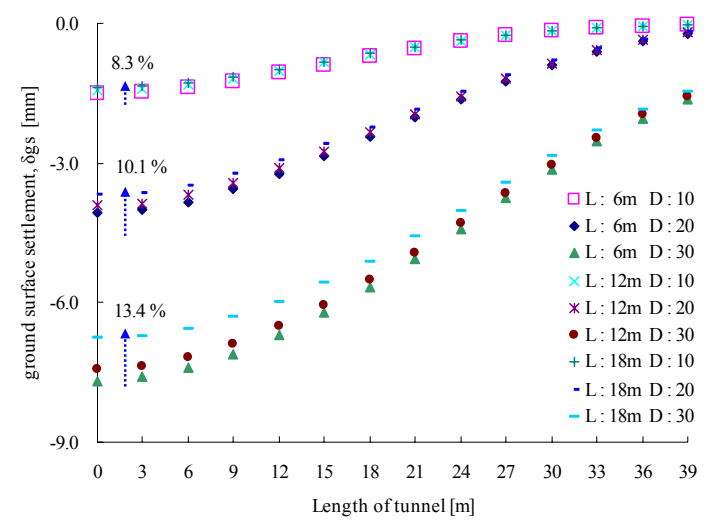

Figure 8. Effect of pipe length on ground surface settlement $\left(\alpha=30^{\circ}, \mathrm{OL}=6 \mathrm{~m}\right)$

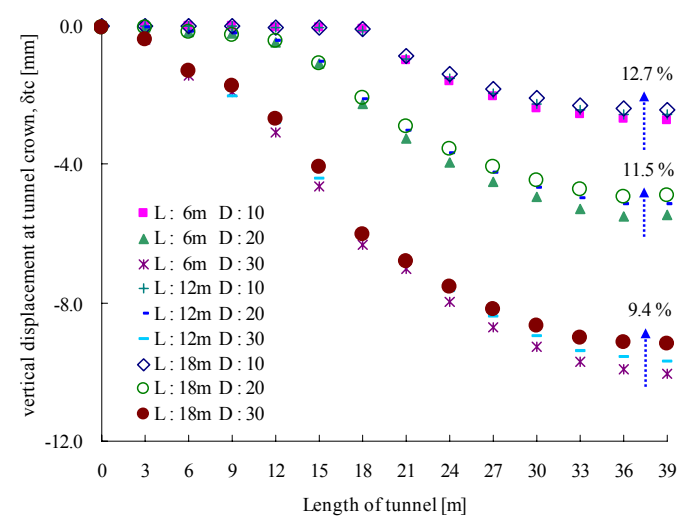

Figure 7. Effect of pipe length on vertical displacement at tunnel crown $\left(\alpha=30^{\circ}, \mathrm{OL}=6 \mathrm{~m}\right)$
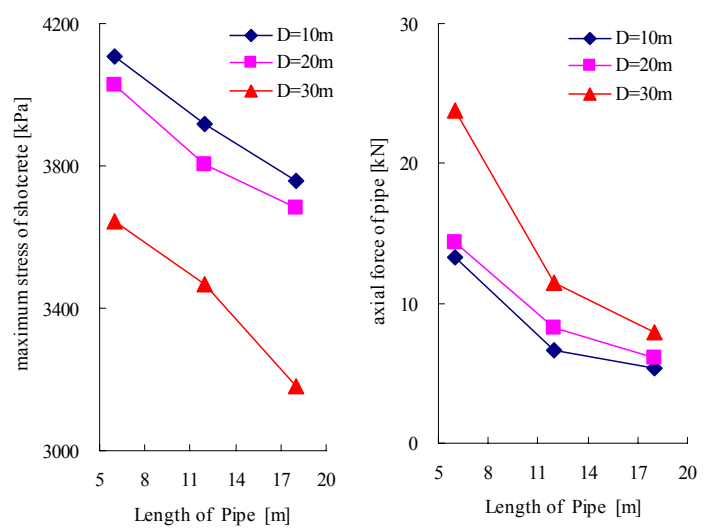

Figure 9. Effect of pipe length on maximum stress of shotcrete and axial force at pipe $\left(\alpha=30^{\circ}, \mathrm{OL}=6 \mathrm{~m}\right)$ 


\section{CONCLUSIONS}

The effects of a pre-improvement support system with a focus on large scale underground excavation have been investigated using a 3D FEM program. From the obtained results, the effect of preimprovement support is found to be more significant as the tunnel scale increases. The ground surface settlement of a large scale tunnel is greater than that of a small scale tunnel, although the ratio of tunnel diameter (D) to reinforced range (R) is the same. Stress acting on the shotcrete is small due to the stress distribution effect. Longer pipe is more effective for the pre-improvement of a large scale tunnel in terms of reducing the axial force acting on the pipe and minimizing the risk of failure and collapse accidents during the excavation procedure. In particular, a yield zone appears on the tunnel face with excessive displacement. Therefore, appropriate pre-improvement of the tunnel face should be conducted. A novel excavation method needs to be developed for large underground excavation so as to maximize the arching effect and to minimize the horizontal displacement at the excavation face. In order to determine the optimized design parameters with respect to the tunnel scale, the critical level in the construction and the characteristics of the ground material should be properly considered.

\section{ACKNOWLEDGMENTS}

This paper was funded by the Korea Institute of Construction and Transportation Technology Evaluation and Planning under the Ministry of Construction and Transportation in Korea (Grant No. 04-C01) and the Smart Infra-Structures Technology Center (SISTeC) under KOSEF.

\section{REFERENCES}

Bernaud, D., 1995. "Numerical simulation of the convergence of a bolt-supported tunnel through a homogenization method." International Journal for Numerical and Analytical Methods in Geomechanics, Vol. 19, pp. 267-288.

Barisone, G., Pigorini, B., and Pelizza, S., 1982. "Umbrella Arch Method for Tunnelling in Difficult Conditions-Analysis of Italian Cases." Proc. $4^{\text {th }}$ Congress International Association of Engineering Geology, New Delhi, Vol. 4, pp. 15-27.

Fizzarotti, E. M., 2001. "Symposium on Reinforced Protection Umbrella Method (RPUM) In Tunnelling." September 21, Seoul, Korea.

Kim, H. T., Lee, B. Y., and Kim, H. M., 1995. "Effect on Tunnel behavior caused by Umbrella Arch Reinforcement Method.” Proc. KSCE Annual Conference, pp. 369-372.

Kim, J. B., Moon, S. J., Whang, Y. C., and Shin, Y. W., 1993. "A Case Study of FEM Analysis on Ground Reinforcement using Horizontal Jet Grout Roofing in Soft Ground Tunneling." Proc. Of the Korean Geotechical Society Conference, pp. 51-56.

Kim, M. I., 1995. "A Study on the Design and Construction of RPC method." Seoul National University of Technology, Industrial Loss Research Institute Report.

Kotake, N., Yamamoto, Y., and Oka, K., 1994. "Design for Umbrella Method based on Numerical Analysis and Field Measurements." Proc. Tunnelling and Ground Conditions, Ed. M. Abdel Salam, pp. 501-508.

Korbin, G. E., and Brekke, T. I., 1976. "Model Study of Tunnel Reinforcement." ASCE, Journal of Geotechnical Engineering, pp. 895-908.

Lee, B. R., Kim, H. T., and Kim, H. M., 1996. "The Application of Nonlinear 3-D Tunnel Analysis Program for the Improved Effects of Steel Pipe Reinforced Multi Step Grouting Method.” Journal of Korean Geotechnical Society, Vol. 12, pp. 5-20.

Lee, I. M., and Kim, Y. J., 1993. "Goundwater Considerations in Tunnel Design." Proc. Of the Korean Geotechical Society Conference, pp. 1-8.

Liu, J., Li, Z., and Zhang, Z., 2004. "Stability analysis of block in the surrounding rock mass of a large underground excavation." Tunnelling and Underground Space Technology, Vol. 19, pp. 35-44.

Pelizza, S., and Peila, D., 1993. "Soil and Rock Reinforcement in Tunnelling." Tunnelling and Underground Space Technology, Vol. 8, pp. 357-372. 